\title{
OPTIMIZATION OF THE PLANT IRRIGATION PROCESS IN PROTECTED SOIL CONSTRUCTIONS
}

Key words: optimization; irradiation process; LED irradiation installation; microprocessor technology; energy intensity; solar radiation; control algorithm; cost of electricity.

\section{Authors' personal details}

1. Galiullin Rustam, Doctor of Technical Sciences, Professor of the power supply and process automation, Federal State Budgetary Educational Institution of Higher Education «Bashkir State Agrarian University», 450001, Ufa, 50-letiya Octyabrya St., 34, e-mail: rustam6274@mail.ru.

2. Jarullin Rinat, Doctor of Technical Sciences, Professor of the Electric Machines and Equipment Chair, Federal State Budgetary Educational Institution of Higher Education «Bashkir State Agrarian University», 450001, Ufa, 50-letiya Octyabrya St., 34, e-mail: jarullin_rb@mail.ru.

3. Kafiev Irshat, Candidate of Technical Sciences, Assistant Professor of the Electric Machines and Equipment Chair, Federal State Budgetary Educational Institution of Higher Education «Bashkir State Agrarian University», 450001, Ufa, 50-letiya Octyabrya St., 34, e-mail: kafiev02@mail.ru.

The paper considers a way to increase the energy efficiency of the technological process of plant irradiation by optimizing the irradiation regimes. This is achieved by fragmentation of the schedule of plant irradiation and the search for the positions of

(с) Галиуллин Р.Р., Яруллин Р.Б., Кафиев И.Р. the fragments of the photoperiod in time, at which the requirement for the daily dose of radiation is satisfied and the minimum cost of the consumed electric energy is ensured.

УДК 681.121 .843

DOI: $10.31563 / 1684-7628-2019-52-4-111-116$

Д. Джураев, М.М. Давлетшин, Ф. Маматов, И. Тоиров, М. Халилов, А. Уришев

\section{МОДЕРНИЗАЦИЯ ТРУБКИ ПИТО - ПРАНДТЛЯ ДЛЯ ОПРЕДЕЛЕНИЯ ДАВЛЕНИЯ ВОЗДУШНОГО ПОТОКА}

\begin{abstract}
Ключевые слова:трубка; прибор; воздушный поток; давление; скорость; вентилятор; опрыскиватель; аспирационный психрометр; микроманометр; точность.
\end{abstract}

Введение. Как известно, основные принципы движения воздуха и жидкости в природе обобщаются, и их движение часто изучается на основе общих уравнений. Для определения динамического давления и скорости движущейся жидкости была создана трубка Пито - Прандтля, установленная к микроманометру ММН-240(5)1.0. Этот прибор применяют для измерения параметров воздушного потока, например, вентилятора опрыскивателя, применяемого для защиты растений. Здесь необходимо отметить, что значения давления жидкости и давления воздушного потока, создаваемого вентилятором, резко отличаются между собой, то есть воздушный поток имеет очень низкое давление по сравнению с давлением движущейся жидкости.

В настоящее время для определения скорости воздушного потока существует много типов и марок анемометров. Например: вращательные (крыльчатки, чашечные), тепловые, вихревые, динамометрические (с трубками Пито), ультразвуковые (акустические), оптические (лазерные допплеровские). Наиболее распространенными являются вращательные анемометры, отличающиеся типом принимающего устройства (чашка или крыльчатка).

Вышеуказанные приборы созданы для измерения скорости воздуха в общем потоке. При исследовании вентиляторов необходимо определить среднее значение давления и скорости воздушного потока на выходе поперечного сечения выходного окна опрыскивателя. Для этого площадь поперечного сечения выходного окна на основе ранее проведенных опытов разделяется на несколько мелких четырехугольников и у каждого по центру определяется давление и скорость воздушного потока.

При проведении научных исследований по изучению давления и скорости воздушного потока, создаваемого вентилятором, применить 
опрыскиватели в вышеназванных приборах не представляется возможным. Поэтому разработка измерительных приборов и определение параметров воздушного потока в нашей стране является одной из наиболее актуальных проблем.

Б.Г. Турбиным [5] были проведены научные исследования по изучению параметров трубки Пито - Прандтля для определения давления и скорости воздушного потока. Им даны рекомендации по повышению его чувствительности.

Б.Г. Турбин [5] при разработке особое внимание уделил рабочей части наконечника трубки, где была выполнена сферическая форма предложенной им конструкции. На наш взгляд, когда рабочая часть наконечника трубки имеет сферическую поверхность, происходит накопление воздушного потока, движущегося с определенной скоростью в соответствии с размерами сферической поверхности. Здесь воздушный поток на какое-то время мгновенно останавливается и потом меняет своё направление движения. Это приводит к тому, что значение измеряемого давления воздушного потока отличается от фактического.

Однако до настоящего времени вопросы по измерению давления и скорости воздушного потока с высокой чувствительностью, создаваемого вентилятором опрыскивателя, используемого для защиты растений, не решены.

Целью данного исследования является разработка и изготовление модернизованной трубки высокой чувствительности для определения давления и скорости воздушного потока, создаваемого вентилятором опрыскивателя, и обоснование её основных параметров.

Литературный обзор. Ученый Франции Анри Пито (1695-1771) в 1732 году разработал, изготовил и применил на практике трубку для измерения полного давления потока движущейся жидкости. Известно, что полное давление представляет собой сумму гидростатического и динамического давления. Ученый Германии Людвиг Прандтль (1875-1953) для определения динамического давления движущейся жидкости в трубе разработанной трубки Пито, установил снаружи вторую трубку с диаметром больше предыдущего, имеющую отверстия с одной стороны и подключенной к микроманометру с отдельными каналами. В то же время каналы были соединены через жидкость, а трубка вставлена в открытую атмосферу, с помощью которой определяется динамическое давление жидкости. Эта трубка названа в честь великих изобретателей и ученых Пито - Прандтля.

В зарубежных странах вопросами по определению давления и скорости жидкости занимались многие ученые. Американские (трубка Хакена) и британские (трубка Брабе) ученые также проводили свои научные исследования в этой области, где разработали различные трубки для определения давления жидкости, названные их именами. Разработка измерительных приборов для определения параметров воздушного потока является одной из наиболее актуальных проблем [1-6]. Исследования Б.Г. Турбина [5] по проектированию и разработке трубки были основой для решения вопроса. Б.Г. Турбин рассматривал проект трубки, где основная часть была выполнена в сферической форме, и предложил соответствующую конструкцию.

Материалы и методы исследования. Мы проанализировали вышеуказанные моменты и разработали конструкцию рабочей части и в целом наконечника трубки для измерения давления воздушного потока, которая устраняет вышеупомянутые дефекты. Нами разработана конструкция наконечника трубки, которая имеет форму конуса и изготовлена в соответствии с нашими параметрами. Наконечник трубки имеет форму острого конуса длиной 50 мм, что приводит к сокращению накопления воздуха возле измеряемого участка по сравнению со сферической формой.

Нами разработана модернизированная трубка для определения давления и скорости воздушного потока. С помощью этой трубки можно определить полное, динамическое и статическое давление воздушного потока. Технологическая схема модернизированной трубки показана на рисунке 1.
Рисунок 1

Технологическая схема модернизированной трубки для определения динамического давления и скорости воздушного потока: 1 -наконечник; 2 - внутренняя трубка; 3 - наружная трубка;4 - штуцеры; 5 - боковые отверстия по А-А: I - канал воздушного потока, движущегося с полным давлением (P); II - канал воздушного потока, поступающего с боковых отверстиях $\left(\mathrm{P}_{\mathrm{cr}}\right)$

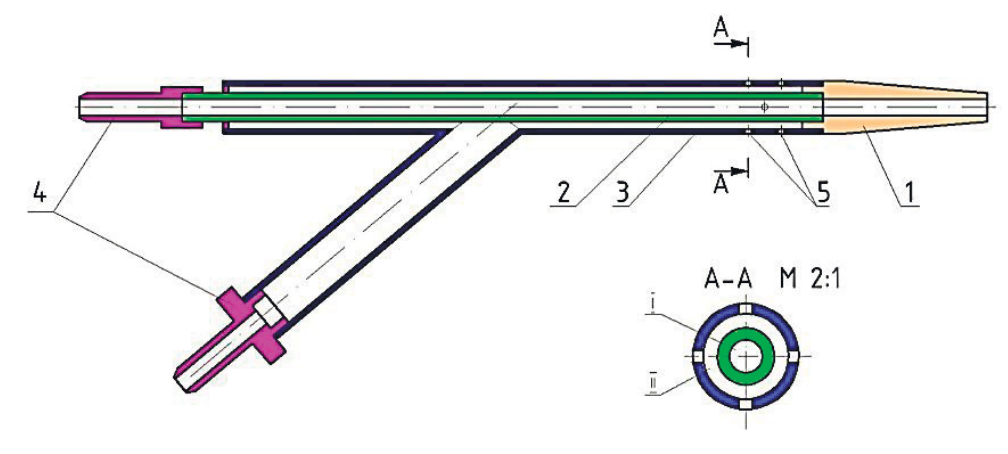


Как показано на рисунке 1, наконечник 1 трубки определенного диаметра (коническая часть) изготавливается отдельно. При этом трубка с меньшим диаметром 2 вставляется во внутреннее отверстие наконечника 1. Трубка большего диаметра 3 с отверстиями 5 вставляется на внешнюю часть наконечника. В конце трубок 2 и 3 были установлены штуцеры 4 для соединения шлангов.

Прибор был испытан под давлением 0,2

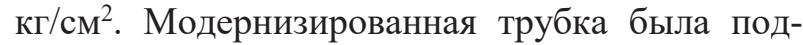
ключена к микроманометру ММН-240(5)-1.0. Для этой цели присоединили первый канал (I), то есть маленькую трубку 2, к микроманометру ММН-240(5)-1.0 с помощью штуцера, имеющего знак $(+)$. При этом поток воздуха с полным давлением через этот канал I поступает в стеклянную трубку прибора. Второй канал трубки (II) соединили к микроманометру МMH-240(5)1.0 с помощью щтуцера со знаком (-). При этом поток воздуха, поступающий из второй трубки 3 , формирует статическое давление $P_{c m}$ в этом канале. Оба канала связаны между собой жидкостью (спиртом), в которой разница статического давления и полного давления воздушного потока равна динамическому давлению $P_{\text {дин, кото- }}$ рое определяется показанием шкалы стеклянной трубки прибора.

Результаты исследований. Перед проведением исследований по определению давления воздушного потока, создаваемого вентилятором универсального навесного опрыскивателя PJG10, на специально разработанном столе был установлен аспирационный психрометр на высоте 2 метра (MВ-4М ГОСТ 6353-52), с помощью которого были определены температура и влажность окружающей среды.

Исследование по изучению параметров воздушного потока с модернизированной трубкой, присоединенной к микроманометру ММН-240 (5)-1.0, проводилось в лаборатории «Узгидрометцентр» Госстандарта Республики Узбекистан.

Во время экспериментальных исследований проводилась запись информации.

На основе проведенных экспериментальных исследований динамическое давление $\left(P_{\text {дин }}\right)$ воздушного потока, создаваемого вентилятором, определяется с использованием модернизированной трубки, подключенной к микроманометру ММН-240(5)-1.0, по следующему выражению:

$$
P_{\text {дин }}=l \cdot K, n \cdot C, \kappa \Gamma / M^{2},
$$

где $l$ - показание шкалы стеклянной трубки прибора (уровень спирта), мм; $K-$ коэффициент угла наклона стеклянной трубки, $\kappa \Gamma / \mathrm{m}^{3} ; n-$ коэффициент, учитывающий разность удельного веса спирта; $C$ - поправочный коэффициент давления, определяемый экспериментальным путем.

Показание шкалы стеклянной трубки прибора (уровень спирта) определялось выражением:

$$
l=l_{1}-a, \text { мм, }
$$

где $a$ - показание шкалы стеклянной трубки прибора (уровень спирта) перед экспериментом исследованием, $м м ; l$ - показание шкалы стеклянной трубки прибора (уровень спирта) в конце эксперимента, мм.

Коэффициент $K$ представляет угол наклона в установке стеклянной трубки прибора, который отмечен на дуге отверстиями и определяется следующим образом:

$$
K=\gamma_{c n} \cdot \sin \alpha, \kappa 2 / \mu^{3},
$$

где $\gamma_{c n}$ - удельный вес заливаемого спирта, предусмотренный по инструкции прибора; $\gamma_{c n}=$ $0,8095 \pm 0,005 \Gamma / \mathrm{cm}^{3}$.

Из-за отсутствия спирта такого удельного веса в приборе можно залить спирт с удельном весом $\gamma_{c n}=0,8844 \Gamma / \mathrm{cm}^{3}$. Известно, что микроманометр ММН-240(5)-1.0 измеряет давление воздуха в диапазоне $0-240 \kappa \Gamma / \mathrm{m}^{2}$, на нем установлена стеклянная трубка, разделенная на 1-300 мм. Микроманометр ММН-240(5)-1.0 настраивается на пять углов наклона относительно горизонтальной оси для повышения точности. В то же время коэффициент $K$, описывающий угол наклона, вводится при установке стеклянной трубки с пятью значениями $K=0,2 ; 0,3 ; 0,4 ; 0,6$; 0,8 . Значение $K$ рассчитывается на основе выражения (3) для пяти отверстий, которые предусмотрены на дуге прибора, и его значение отражается в каждом отверстии. Для каждого значения угла наклона $K$ стеклянной трубки микроманометр ММН-240(5)-1.0 определяет давление воздушного потока в пределах этого диапазона. Например, в микроманометре ММН-240(5.0)1.0 установлена стеклянная трубка под углом $K$ $=0,2$. Определяем диапазон измерения прибора, для этого максимальное значение (верхний предел измерения) измерения прибора умножаем на коэффициент $K$. Тогда: $240 \times 0,2=48 \kappa \Gamma / \mu^{2}$, т. е. его верхний предел измерения давления воздуха составляет 48 кг/ $\mathrm{M}^{2}$. На основе полученных данных по результатам исследований построена номограмма зависимости динамического давления и скорости воздушного потока от показаний шкалы стеклянной трубки микроманометра ММН-240(5)-1.0 с модернизированной трубкой при вышеуказанных значениях коэффициента $K$ (рисунок 2). На приведенном графике каждая закономерность состоит из трех линий, лежащих друг на друге. В лаборатории «Узгидромет- 
центр» Госстандарта Республики Узбекистан проведены в одинаковых условиях параллельные исследования на приборе ПАТ № 016 и ДМЦ-01 (эталон) и на микроманометре ММН240(5)-1.0 с модернизированной трубкой. В результате исследований проводилась запись информации, на основании которой построены закономерности, определена эмпирическая формула и построены график закономерности.
Анализ вышеприведенных данных выявил, что показатели микроманометра ММН-240(5)1.0 с модернизированной трубкой имеют высокую точность. На горизонтальной оси графика расположено значение динамического давления $P_{\text {дин }}$ и скорости $V$ воздушного потока, а на вертикальной оси указаны значения шкалы стеклянной трубки $l$ микроманометра ММН-240(5)1.0 с модернизированной трубкой.
Рисунок 2

Номограмма для определения динамического давления и скорости воздушного потока в зависимости от показаний шкалы стеклянной трубки микроманометра ММH240(5)-1,0 с модернизированной трубкой

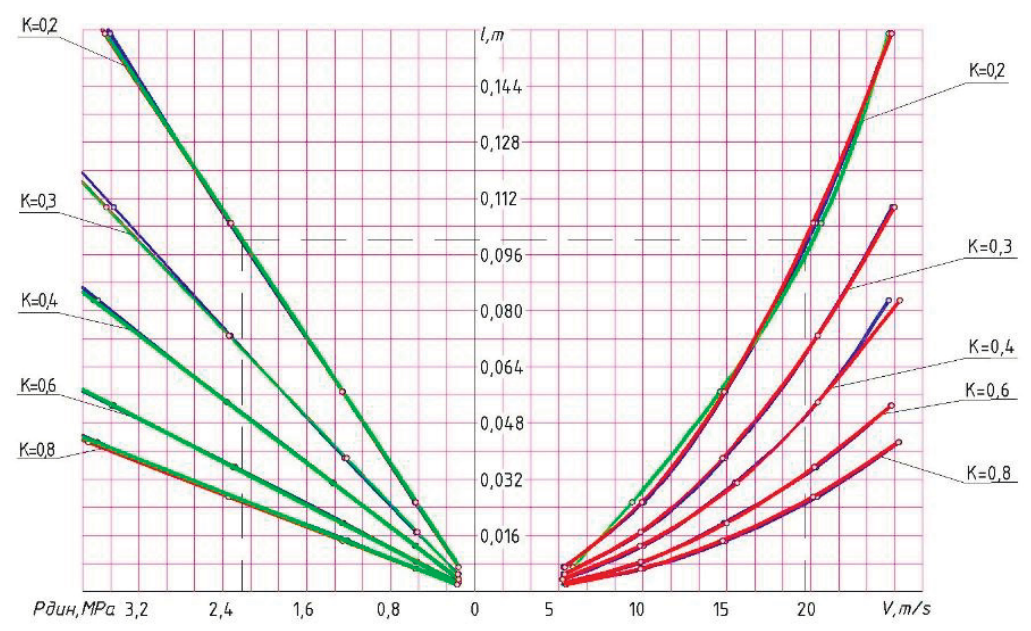

ческого давления и скорости воздушного потока, определенных микроманометром ММН240(5)-1.0 с присоединением модернизированной трубки очень близки к контрольным показателям (эталону) и даже во многом равны им, и их разность не превышает допустимого предела.

Получены следующие эмпирические зависимости, на основе которых составлена программа на базе Excel, позволяющая определить динамическое давление и скорость воздушного потока в зависимости от показания шкалы стеклянной трубки и коэффициента прибора $K$ микроманометра ММН-240(5)-1.0 с модернизированной трубкой, которые приведены ниже:

Для определения значения динамического давления:

1. При $K=0,2 ; P_{\text {дин }}=22,17 l-0.0084, M P a . R^{2}=0,9999$.

2. При $K=0,3 ; P_{\text {дин }}=32,133 l+0.0004, M P a . R^{2}=1$.

3. При $K=0$,4; $P_{\text {дин }}=43,708 l-0.0004, M P a \cdot R^{2}=1$.

4. При $K=0,6 ; P_{\text {дин }}=64,762$ l, MPa. $R^{2}=1$.

5. При $K=0,8 ; P_{\text {дин }}=85,065 l-0.0003, M P a . R^{2}=1$.

Для определения значения скорости:
1. При $K=0,2 ; V=-506,15 l^{2}+207,62 l+4,4145, \mathrm{~m} / \mathrm{s} . R^{2}=0,9964$.
2. При $K=0,3 ; V=-1103,9 l^{2}+307,42 l+4,3657, \mathrm{~m} / \mathrm{s} . R^{2}=0,9959$.
3. При $K=0,4 ; V=-1765,8 l^{2}+393,83 l+4,3978, \mathrm{~m} / \mathrm{s} . R^{2}=0,9975$.
4. При $K=0,6 ; V=-4519,7 l^{2}+622,28 l+4,3208, \mathrm{~m} / \mathrm{s} . R^{2}=0,996$.
5. При $K=0,8 ; V=-7450,1 l^{2}+803,28 l+4,381, \mathrm{~m} / \mathrm{s} . R^{2}=0,9961$.

Выводы. Разработана и изготовлена модернизованная трубка к микроманометру ММH240(5)-1.0, которая с требуемой точностью определяет динамическое давление и скорость воз- душного потока, создаваемого вентилятором. Получен сертификат «Узгидрометцентр» Госстандарта Республики Узбекистан (№ 170, 15.03.2017). Найдены эмпирические зависимо- 
сти, на основе которых составлена компьютерная программа на базе Excel, позволяющая определить динамическое давление и скорость воз- душного потока в зависимости от показаний шкалы прибора с требуемой точностью.

\section{Библиографический список}

1. Попов, С.Г. Измерение воздушных потоков [Текст] / С.Г. Попов. М.-Л., 1947. 296 с.

2. Физические измерения в газовой динамике и при горении [Текст] / Пер. с англ.Ч. 1-2. М.: Изд-во иностранной литературы, 1957. 483 с.

3. Горлин, С.М. Аэромеханические измерения [Текст] / С.М. Горлин, И.И. Слезингер. М.: Наука, 1964. 720 с.

4. Петунин, А.Н. Приемники для измерения давлений и скорости в газовых потоках
[Текст] / А.Н. Петунин // Промышленная аэродинамика. 1960. № 19. С. 78-174.

5. Турбин, Б.Г. Вентиляторы сельскохозяйственных машин [Текст] / Б.Г. Турбин. Л.: Машиностроение, 1968. 159 с.

6. Вайсман, М.Р. Вентиляционные и пневмотранспортные установки [Текст] / М.Р. Вайсман, И.Я. Грубиян. М.: Колос, 1984. 367 с.

\section{Сведения об авторах}

1. Джжураев Дюжума, доцент, Каршинский инженерно-экономический институт (КИЭИ), г. Карши, Узбекистан.

2. Давлетиин Мударис Мубарякианович, профессор, ФГБОУ ВО Башкирский ГАУ, г. Уфа, Башкортостан.

3. Маматов Фармон, профессор, Каршинский инженерно-экономический институт (КИЭИ), г. Карши, Узбекистан.

4. Тоиров Илхом, доцент, Каршинский инженерно-экономический институт (КИЭИ), г. Карши, Узбекистан.

5. Халилов Мухтор, старший преподаватель, Каршинский инженерно-экономический институт (КИЭИ), г. Карши, Узбекистан.

6. Уришев Адхамжжон, ассистент, Ташкентский институт инженеров ирригации и механизации сельского хозяйства (ТИИИМСХ), г. Ташкент, Узбекистан.

В статье приведены результаты научно-исследовательской работы по модернизации трубки к микроманометру ММН-240(5)-1.0 для определения давления и скорости воздушного потока. Описаны устройства и принцип работы модернизированной трубки и приведены результаты ее исследований в приборе ПАТ № 016 и ДМЦ-01.М при определении давления и скорости воздушного потока. По результатам поверки микроманометра ММН-240(5)-1.0 с модернизированной трубкой Госстандартом «Узгидрометцентр» выдан сертификат № 170 (15.03.2017 г.).

D. Jurayev, M. Davletshin, F. Mamatov, I. Toirov, M. Khalilov, A. Urishev

\section{IMPROVED PITOT - PRANDTL TUBE USED TO MEASURE AIR FLOW PRESSURE}

Key words: tube; device; air flow; pressure; velocity; fan; sprayer; aspirated psychrometer; micromanometer; accuracy.

\section{Authors' personal details}

1. Dzhuraev Dzhuma, Associate Professor, Karshi Engineering and Economic Institute, Karshi, Uzbekistan.

2. Davletshin Mudaris, Professor, Federal State Budgetary Educational Institution of Higher Education «Bashkir State Agrarian University», Ufa, Bashkortostan.

3. Mamatov Farmon, Professor, Karshi Engineering and Economic Institute, Karshi, Uzbekistan.

4. Toirov Ilkhom, Associate Professor, Karshi Engineering and Economic Institute, Karshi, Uzbekistan.

5. Khalilov Mukhtor, Senior Lecturer, Karshi Engineering and Economic Institute, Karshi, Uzbekistan.

6. Urishev Adhamjon, Teaching Assistant, Tashkent Institute of Irrigation and Farm Mechanization Engineers, Tashkent, Uzbekistan. 
The article presents the study results on improving the Pitot tube for the MMN-240(5)-1.0 micromanometer used to measure air flow pressure and velocity. The design and operation principle of the improved tube are described. For the analysis the PAT no. 016 and DMTs-01.M units employed the study tube to measure air flow pressure and velocity. The operation of the MMN-240(5)-1.0 micromanometer fitted with the improved tube was examined and certificate no. 170 (dated 03.15.2017) was issued by the State Standard agency of Uzbekistan «Uzhydrometcenter».

(С) Джураев Д., Давлетшин М.М., Маматов Ф., Тоиров И., Халилов М., Уришев А.

УДК 539.3:636.2

DOI: $10.31563 / 1684-7628-2019-52-4-116-123$

П.В. Дородов, М.Р. Кудрин, А.В. Костин, В.А. Николаев

ИССЛЕДОВАНИЕ ФИЗИКО-МЕХАНИЧЕСКИХ СВОЙСТВ ПОЛИМЕРНО-ПЕСЧАНОЙ СМЕСИ ДЛЯ ПОЛОВ КОРОВНИКОВ

\author{
Ключевые слова: покрытие пола; стойло; полимерно-песчаная смесь; механические характе- \\ ристики; прочность; жесткость; ползучесть; сжатие; изгиб; удар; усталость.
}

Введение. Известно, что применение полимерных композиционных материалов в строительстве и машиностроении даёт значительный экономический эффект, например, позволяет сэкономить от $5 \%$ до $30 \%$ веса проектируемого изделия. Одним из видов композитных материалов является полимерно-песчаная смесь (ППС), к основным преимуществам которой можно отнести: высокую коррозионную и химическую стойкость; возможность использования в условиях повышенной влажности, сезонных и суточных температурных перепадов; возможность поставки в виде отдельно собранных, легко транспортируемых, заменяемых и наращиваемых модульных конструкций; снижение расходов на изготовление изделий, их монтаж и эксплуатацию. Однако внедрение таких изделий требует исследования и подтверждения их свойств соответствующим нормативным требованиям. Полимерно-песчаная плитка характеризуется как прочный, надежный, долговечный материал и в качестве покрытия пола в стойлах для крупного рогатого скота является оптимальным. Однако в местах постоянного нахождения животных плитка подвергается большим местным нагрузкам и механическим воздействиям переменного характера. Это приводит к сокращению срока эксплуатации данного типа полов и повышает процент травмируемых животных. Поэтому при проектировании коровников необходимо обосновать конструкционные параметры плитки при различных видах сопротивления, расчет которых зависит от механических характеристик ППС. В работе представлены результаты исследования механических свойств ППС при статическом сжатии и изгибе, ударе и циклическом нагружении. Так, удельная прочность ППС при сжатии в 2,4...5,5 раза и в $3,8 \ldots 12,3$ раза ниже по сравнению со сталью и серым чугуном соответственно. Жесткость ППС при сжатии более чем в 1672 и 1338 раз, а при изгибе более чем в 255 и 147 раз ниже по сравнению с углеродистой конструкционной сталью и серым чугуном соответственно. Прочность при ударной нагрузке образцов из ППС в $3,5 \ldots 13,7$ раз выше серого чугуна и соизмерима с некоторыми марками углеродистой конструкционной стали. Удельная усталостная прочность ППС более чем в 4,8 и в 2,3 раза ниже углеродистой конструкционной стали и серого чугуна соответственно.

Сегодня для снижения материалоемкости производства постепенно внедряются дешевые, лёгкие, прочные и долговечные композитные материалы, например полимерно-песчаные изделия, которые вытесняют с рынка устаревшие аналоги, производимые из бетона и металла (рисунок 1).

И это не удивительно - при сравнительно невысокой стоимости полимерно-песчаные элементы не боятся климатических перепадов температуры и влажности, имеют высокую коррозионную и химическую стойкость [1]. Они изготавливаются из дешевого сырья: измельченных полимерных бытовых отходов и речного песка. Ожидаемый срок службы каждой такой детали составляет не менее 10 лет при эксплуатации в самых сложных условиях [2]. Однако внедрение таких изделий, в том числе на предприятиях АПК, требует исследования и подтверждения их свойств соответствующим нормативным требованиям [1-4]. 